\title{
Global Cognitive Function is Associated with Sex, Educational Level, Occupation Type, and the Speech Recognition Rate in Older Chinese Adults: A Single- Center, Prospective, Cross- Sectional Study
}

\section{Hailing Gu}

West China Hospital of Sichuan University

Xinyi Yao

West China Hospital of Sichuan University

Cong Diao

West China Hospital of Sichuan University

Min Liu

West China Hospital of Sichuan University

Weili Kong

West China Hospital of Sichuan University

Haotian Liu

West China Hospital of Sichuan University

Yun Zheng

West China Hospital of Sichuan University

Zhaoli Meng ( $\square$ lucy-mengzhaoli@163.com)

West China Hospital of Sichuan University

\section{Research Article}

Keywords: Age-related hearing loss, Mild cognitive impairment, Mini-Mental State Examination

Posted Date: February 7th, 2022

DOI: https://doi.org/10.21203/rs.3.rs-1322769/v1

License: (c) (1) This work is licensed under a Creative Commons Attribution 4.0 International License. Read Full License 


\section{Abstract}

Background: The development of cognitive impairment may be delayed if its risk factors are identified, it can be detected, its developmental trend can be predicted, and early intervention can be performed. This study primarily aimed to investigate the association between global cognitive function and hearing loss, educational level, and occupation type, and to determine any differences in such associations according to sex among older Chinese adults.

Methods: In this cross-sectional study, we prospectively recruited individuals in one ear, nose, and throat outpatient clinic who were above 55 years of age and could write independently, with no diagnosis of severe vision impairment. Audiometric examinations included otoscopy, acoustic immittance, pure-tone audiometry, and speech audiometry for each ear. Cognitive function was evaluated by using the Chinese version of the Mini-Mental State Examination (MMSE). Univariable linear regression analyses were conducted to assess the relationship between each variable and MMSE score. Multivariable linear regression analyses were performed to evaluate the relationship between variables and MMSE scores after adjusting for independent variables that were statistically significant in the univariable analyses.

Results: We enrolled 219 individuals, including 98 men (mean \pm standard deviation age, $63.08 \pm 6.64$ years) and 121 women (62.64 \pm 7.17 years). The overall MMSE scores of the normal hearing and mild, moderate, and severe-to-profound hearing loss groups were $24.53 \pm 3.10,24.36 \pm 3.92,23.32 \pm 3.88$, and $20.92 \pm 6.53$, respectively. MMSE scores were higher among participants with higher educational levels $(p<0.001)$ and were significantly correlated with occupation type $(p<0.001)$. MMSE scores were significantly higher in men than in women $(p<0.001)$. However, upon analysis of the five subdomains, significant differences were only observed for attention and calculation $(p<0.001)$ and language $(p=0.011)$. We further explored whether educational level is related to the cognitive differences between the sexes by comparing the distribution of educational levels between men and women, with the chisquare test; there was no significant difference in educational level between the sexes $(p=0.070)$.

Conclusions: We discovered statistically significant relationships between global cognitive function and sex, educational level, and occupation type. Sex-specific strategies may be required to improve healthcare policies.

\section{Background}

It is well-known that cognitive impairment $(\mathrm{Cl})$ affects the quality of life, social functioning, and well-being of older adults.As the number of older adults is rising with the average life expectancy,this is becoming a severe social and public health problem. The prevalence of mild cognitive impairment $(\mathrm{MCl})$ reported in population-based epidemiological studies ranges from $3 \%$ to $19 \%$ in adults older than 65 years [1]. $\mathrm{MCl}$ can act as a transitional stagein the development of dementia with a range of conversion of $10 \%-15 \%$ per year, although it does not interfere substantially with individuals' daily activities[2]. Worldwide, approximately 50 million people live with dementia, and this number is projected to increase to 152 
million by 2050, rising particularly in low- and middle-income countries where around two-thirds of people with dementia live[3].

In addition to the development of pharmacological preventions and treatments for $\mathrm{Cl}$, modifiable risk factors need to be examined and addressed. Many studies have been conducted in the attempt to identify the risk factors for cognitive decline [4], with many[5,6] pointing toward age-related hearing loss (ARHL) as an independent risk factor.Depending on its severity, ARHLseems to play a significant role in cognitive decline. However, recentquantitative studies of the relationship between hearing loss $(\mathrm{HL})$ and cognitive function weremainly based on self-reported measures[7-9], rather than on a combination of subjective measures and objective audiometry.

Having a higher educational leveland/or a complex occupational roleare generally considered to be protective against cognitive decline[10,11] and to contribute to cognitive reserve.Other putative protective factors may themselves also be caused by a higher educational level and occupational complexity[12].It should also be noted that, in one study[13],a higher educational level decreased the risk of dementia, whereas occupational complexity was not associated with dementia.Furthermore, a couple of studies $[13,14]$ revealed that the cut-off point at which educational level is protective against dementia may vary depending on the age composition of the cohort in question. Therefore, the influence of education and occupation type on cognitive performance in older adultsis unclear.

In China, the prevalence of $\mathrm{Cl}$ was $62.7 \%$ in women and $45.4 \%$ in men over 75 years of age in one study [15], althoughthere are differences in hypotheses and results between studies regarding factors related to cognitive decline between the sexes among older individuals. The results of certain studies $[16,17]$ seem to provide an explanation for the bettercognitive performanceof men than women:the effects of endogenous estrogen decline at older age.Older women are more likely to develop dementia than men of the same age, probably in part because, on average, older women have had less education than older men[5].When adjusting for educational status, it seems that women typically have a better verbal memory than men,which is consistent with the hypothesis of cognitive reserve[18]. However, the difference incognitive performance between the sexesafter adjustment for age remains unknown.

The development of $\mathrm{Cl}$ may be delayed ifits risk factors are identified, it can be detected,its developmental trend canbe predicted, and early interventioncan be performed.Therefore, the main aim of this study was to investigate the associations between global cognitive function (as defined by using Mini-Mental State Examination [MMSE] scores) andHL, educational level, and occupation type,and to explore whether there are any differences in such associations according to sex among older Chinese adults.

\section{Methods}

\section{Study population}

In this cross-sectional study, weprospectively recruited individuals in the ear, nose, and throat outpatient clinic of West China Hospital from June 2020 to February 2021. Individuals were included in this study if 
they were aged 55 years or older, could write independently, and had no diagnosis of severe vision impairment. Participants were excluded if they were living alone, had a history of more than $30 \mathrm{~min}$ of unconsciousness due to trauma, had first-degree relatives who had been diagnosed with dementia, or had hypertension (systolic blood pressure $\geq 140 \mathrm{mmHg}$ and/or diastolic blood pressure $\geq 90 \mathrm{mmHg}$ )[19], diabetes mellitus (glycated hemoglobin $>6.5 \%$ )[20], hemorrhaging, cerebral infarction, cerebrovascular disease diagnosed with magnetic resonance imaging, a body mass index $>24$ or $<18.2 \mathrm{~kg} / \mathrm{m}^{2}$, thyroid dysfunction, abnormal electrocardiogram characteristics, chronic obstructive pulmonary disease (COPD Assessment Test score $\geq 11$ ] [21], syphilis, or unilateral/bilateral conductive/mixed HL. This study was approved by the Biomedical Research Ethics Committee of West China Hospital (No.2020285). All participants voluntarily signed an informed consent form.

\section{Information acquisition}

This study was conducted via face-to-face interviews with highly trained researchers. Demographic information (including name, sex, date of birth, occupation type, educational level, etc.) and individual medical history (dementia, hypertension, hemorrhaging, cerebral infarction, cerebrovascular disease, etc.) were collected by using a pre-designed questionnaire which was analyzed per individual by researchers.

\section{Audiometric examinations}

A combination of otoscopy, acoustic immittance, pure-tone audiometry, and speech audiometry was conducted for each ear in a soundproof room with ambient noise $<30 \mathrm{dBA}$ (A-weighted sound pressure level). Bilateral pure-tone hearing thresholds at frequencies of $0.25,0.5,1,2,4$, and $8 \mathrm{kHz}$ were measured at 5-dB increments in decibels hearing level (dB HL). Pure-tone threshold average (PTA) of the better ear for four frequencies $(0.5,1,2$, and $4 \mathrm{kHz})$ were adopted to define participants' degree of hearing, according to guidelines published by the World Health Organization (1997)[22]. The cut-off values for mild, moderate, severe, and profound hearing loss were 25-, 40-, 60-, and 80-dB HL, respectively. The speech recognition rate was determined with speech audiometry. The acoustic immittance test consisted of tympanometry and the acoustic reflex decay test, and was used to measure the state of the middle ear and the function of the cochlear and facial nerves.

\section{Cognitive assessment}

Cognitive function was evaluated by using the Chinese version of theMMSE. The MMSE has a 30-point scale and is commonly usedto screen individuals for $\mathrm{Cl}$, with high sensitivity and specificity.It covers five cognitive domains: orientation, registration, attention and calculation, recall, and language. The diagnostic criteria for $\mathrm{Cl}$ varied with the participant's educational level. Clwas defined as an MMSE score $<17$ in the illiterate group, $<20$ in the primary-school group, $<23$ in the junior/high-school, and $<24$ in the "above" group.

\section{Statistical analysis}


Continuous variables (age, duration of HL, PTA, and speech recognition rate) are described as means and standard deviations. Categorical variables (binary variable: sex; multi-categorical variables: educational level and occupation type) are presented as numbers with percentages. Student's t-test, one-way analysis of variance,the Mann-Whitney $U$ test, and the Kruskal-Wallis test were used for comparison of continuous variables among groups, and the chi-squared test or Fisher's exact test was used for comparison of categorical variables among groups, as appropriate. Univariable linear regression analyses were conducted to assess the relationship between each variable and the MMSE score. Multivariable linear regression analyses were performed to evaluate the relationship between variables and the MMSE score after adjusting for independent variables that were statistically significant in the univariable analyses.

All statistical analyses were performed with IBM SPSS Statistics for Windows, version 25.0(IBM Corp., Armonk, NY, USA) and GraphPad Prism 9.0 software (GraphPad Software, Inc., San Diego, CA, USA), and a two-sided P-value $\leq 0.05$ was considered statistically significant.

\section{Results}

\section{Demographic characteristics}

After strict observance of the inclusion and exclusion criterion, a total of 219 individuals were enrolled in this study, including 98 men (44.7\%; mean age, 63.08 \pm 6.64 years) and 121 women (55.3\%; mean age, $62.64 \pm 7.17$ years). With regard to $\mathrm{HL}, 64(29.2 \%)$ participants had normal hearing, $70(32.0 \%)$ had $\mathrm{mild} \mathrm{HL}$, 73(33.3\%) had moderate HL, and 12(5.5\%) had severe-profound HL (severe and profound HL groups were combined because of the small sample size). Participant age, duration of HL, PTA, and the speech recognition rate differedamong the four groups. Individuals with worse hearing were typically older, had had $\mathrm{HL}$ for a longer time, had a higher PTA, and had a worse speech recognitionrate than those with better hearing. However, there were no differences in sex, educational level, or occupation type among the groups. The specific sociodemographic and hearing characteristics of the participants are summarized in Table 1.

Table 1. Socio-demographic characteristics of all participants by hearing loss degree 


\begin{tabular}{|c|c|c|c|c|c|}
\hline \multirow[t]{2}{*}{ Characteristics } & \multicolumn{4}{|c|}{ Hearing-loss degree } & \multirow{2}{*}{$\begin{array}{l}\mathrm{P} \\
\text { Value }\end{array}$} \\
\hline & $\begin{array}{l}\text { Normal } \\
(n=64)\end{array}$ & $\begin{array}{l}\text { Mild } \\
(n=70)\end{array}$ & $\begin{array}{l}\text { Moderate } \\
(n=73)\end{array}$ & $\begin{array}{l}\text { Severe- } \\
\text { profound } \\
(n=12)\end{array}$ & \\
\hline Age, mean (SD), years & $59.92(4.62)$ & $63.23(6.83)$ & 64.42(7.51) & $66.42(9.22)$ & 0.001 \\
\hline \multicolumn{6}{|l|}{ Sex, n (\%) } \\
\hline Male & 23(23.47) & 33(33.67) & $37(37.75)$ & $5(5.10)$ & 0.146 \\
\hline Female & 41(33.88) & $37(30.58)$ & $36(29.75)$ & $7(5.79)$ & \\
\hline \multicolumn{6}{|l|}{ Education, n (\%) } \\
\hline Illiteracy & $2(16.67)$ & $3(25.00)$ & $5(41.67)$ & $2(16.67)$ & \\
\hline Primary school & $6(23.08)$ & $9(34.62)$ & $11(42.31)$ & $0(0.00)$ & 0.249 \\
\hline Junior/ high school & $36(29.51)$ & $36(29.51)$ & 42(34.43) & $8(6.56)$ & \\
\hline $\begin{array}{l}\text { Undergraduate/ master/ } \\
\text { PhD }\end{array}$ & $20(33.90)$ & $22(37.29)$ & $15(25.42)$ & 2(3.39) & \\
\hline \multicolumn{6}{|l|}{ Occupation type } \\
\hline None & 18(29.03) & $18(29.03)$ & $20(32.26)$ & 6(9.68) & 0.668 \\
\hline Retired & $35(32.71)$ & $33(30.84)$ & 36(33.64) & $3(2.80)$ & \\
\hline Physical labor & $6(24.00)$ & $9(36.00)$ & $8(32.00)$ & $2(8.00)$ & \\
\hline Mental labor & $5(20.00)$ & $10(40.00)$ & $9(36.00)$ & $1(4.00)$ & \\
\hline $\begin{array}{l}\text { Duration of } \mathrm{HL} \text {, mean (SD), } \\
\text { years }\end{array}$ & $0.33(1.37)$ & $1.87(4.47)$ & $5.91(11.23)$ & $13.21(15.15)$ & 0.000 \\
\hline PTA, mean (SD), dB HL & $15.94(4.71)$ & $31.18(5.40)$ & $49.38(5.78)$ & $66.87(10.92)$ & 0.000 \\
\hline $\begin{array}{l}\text { Speech recognition rate, } \\
\text { mean (SD), \% }\end{array}$ & $98.56(2.61)$ & $94.57(10.64)$ & $49.38(5.78)$ & $66.88(10.92)$ & 0.000 \\
\hline
\end{tabular}

SD, standard deviation; dB HL, decibel hearing level; PTA, pure-tone thresholds average

\section{Association between cognition and hearing}

The overall MMSE scores of the normal hearing andmild, moderate, and severe-profound $\mathrm{HL}$ groups were $24.53 \pm 3.10,24.36 \pm 3.92,23.32 \pm 3.88$, and $20.92 \pm 6.53$, respectively. There was no significant association between MMSE score and the degree of $H L(p=0.09)$. Linear regression analysis revealed that the MMSE score was negatively correlated tothe PTA $\left(R^{2}=0.07, p<0.001\right.$, Figure 1$)$ and positively related to the speech recognition rate $\left(R^{2}=0.09, p<0.001\right.$, Figure 2$)$. 
MMSE scores were higher among participants with higher educational levels $(p<0.001)$. The overall MMSE scores of the illiterate, primary-school, junior/high-school, and undergraduate/master's/PhD groups were $16.67 \pm 3.87,20.35 \pm 3.46,24.16 \pm 3.23$, and $26.31 \pm 2.49$, respectively. The above trend among the four education levels was also present in the MMSE subdomains of orientation $(p<0.001)$, attention and calculation $(p<0.001)$, recall $(p<0.001)$, and language $(p<0.001)$, but not in that of registration $(p=0.142$, Figure 3$)$.

\section{Association between cognition and occupation}

MMSE scores were significantly correlated with occupation type $(\mathrm{p}<0.001)$. The overall MMSE scores of the unemployed, retired, physical labor, and mental labor groups were $22.00 \pm 4.53,24.94 \pm 2.84$, $26.28 \pm 2.64$, and $21.52 \pm 4.52$, respectively. The distribution of the overall MMSE score and those for different occupation types is illustrated in Figure 4.

\section{Association between cognition and sex}

MMSE scores were significantly higher in men than in women $(p<0.001)$. However, uponanalysis of the five subdomains, significant differenceswere only observed for attention and calculation $(p<0.001)$ and language $(p=0.011)$. Scores did not differ between sexes in terms of orientation $(p=0.091)$, registration $(p=0.985)$, or recall $(p=0.128)$ (Figure 5). We further exploredwhether educational level is related to the cognitive differences between the sexesby comparing the distribution of educational levels between men and women, with the chi-squared test.Thisanalysis revealed no significant difference in the educational levelbetween the sexes $(p=0.070$, Table 2$)$.

Table 2. The distribution difference of educational level between males and females

\begin{tabular}{|llllll|}
\hline $\begin{array}{l}\text { Sex, } \mathbf{n} \\
(\%)\end{array}$ & \multicolumn{2}{l}{ Education level } & & & \\
\cline { 2 - 5 } & Illiteracy & $\begin{array}{l}\text { Primary } \\
\text { school }\end{array}$ & $\begin{array}{l}\text { Junior/ high } \\
\text { school }\end{array}$ & $\begin{array}{l}\text { Undergraduate/ master/ } \\
\text { PhD }\end{array}$ & $\begin{array}{l}\text { P- } \\
\text { value }\end{array}$ \\
\hline Male & $2(2.04)$ & $9(9.18)$ & $55(56.12)$ & $32(32.65)$ & 0.070 \\
\hline Female & $10(8.26)$ & $17(14.05)$ & $67(55.37)$ & $27(22.21)$ & \\
\hline
\end{tabular}

\section{Association of MMSE score with measured characteristics}

Table 3 summarizes the results of the linear regression analyses. In the univariable analysis, the MMSE score was significantly associated with sex, educational level, occupation type, duration of HL, PTA, and speech recognition rate (all $p<0.05)$. In the multivariable analysis, the duration of $\mathrm{HL}(p=0.794)$ and PTA $(p=0.212)$ were excluded from the model. MMSE scores of retired participants and those with a physical job did not differ from those of unemployed participants ( $p=0.872$ and $p=0.239$, respectively).

Table 3. Association of MMSE score with measured characteristics in the simple and multiple linear regression analysis 


\begin{tabular}{|c|c|c|c|c|c|c|}
\hline \multirow[t]{2}{*}{ Characteristics } & \multicolumn{3}{|c|}{ Univariate analysis } & \multicolumn{3}{|c|}{ Multivariate analysis } \\
\hline & $\beta$ & $95 \% \mathrm{Cl}$ & $\begin{array}{l}\text { P } \\
\text { Value }\end{array}$ & $\beta$ & $95 \% \mathrm{Cl}$ & $\begin{array}{l}P \\
\text { Value }\end{array}$ \\
\hline Age & -0.06 & $\begin{array}{l}-0.14 \\
-0.01\end{array}$ & 0.096 & -0.027 & - & 0.612 \\
\hline \multicolumn{7}{|l|}{ Sex } \\
\hline Male & Reference & & & - & - & - \\
\hline Female & -1.82 & $\begin{array}{l}-2.85 \\
-0.79\end{array}$ & 0.001 & -1.30 & $\begin{array}{l}-2.11 \\
-0.50\end{array}$ & 0.002 \\
\hline \multicolumn{7}{|l|}{ Education } \\
\hline Illiteracy & Reference & & & - & - & - \\
\hline Primary school & 3.68 & $1.54,5.82$ & 0.001 & 2.79 & $0.73,4.85$ & 0.008 \\
\hline Junior/ high school & 7.49 & $5.63,9.35$ & $<0.001$ & 6.46 & $4.67,8.23$ & $<0.001$ \\
\hline $\begin{array}{l}\text { Undergraduate/ master/ } \\
\text { PhD }\end{array}$ & 9.638 & $\begin{array}{l}7.69 \\
11.58\end{array}$ & $<0.001$ & 8.13 & $\begin{array}{l}6.24 \\
10.02\end{array}$ & $<0.001$ \\
\hline \multicolumn{7}{|l|}{ Occupation type } \\
\hline None & Reference & & & & & \\
\hline Retired & 2.94 & $1.82,4.07$ & $<0.001$ & 0.01 & - & 0.872 \\
\hline Physical labor & 4.28 & $2.60,5.96$ & $<0.001$ & 0.07 & - & 0.239 \\
\hline Mental labor & -0.48 & $-2.16,1.20$ & 0.573 & -1.92 & $\begin{array}{l}-3.17 \\
-0.66\end{array}$ & 0.003 \\
\hline Duration of hearing loss & -0.08 & $-0.14,0.01$ & 0.02 & -0.01 & - & 0.794 \\
\hline PTA & -0.07 & $-0.10,0.03$ & $<0.001$ & -0.08 & - & 0.212 \\
\hline Speech recognition rate & 0.07 & $0.04,0.10$ & $<0.001$ & 0.05 & 0.03 .0 .08 & $<0.001$ \\
\hline
\end{tabular}

$\beta$, regression coefficient; $\mathrm{Cl}$, confidence interval; PTA, pure-tone thresholds average.

\section{Discussion}

Our study aimed to investigate the relationship between $\mathrm{HL}$, educational level, occupation type, and cognition function among older Chinese adults, and whether such associations differ according to sex. Upon univariate analysis, we identified six factors associated with $\mathrm{Cl}$ : sex, educational level, occupation type, duration of HL, PTA, and the speech recognition rate. After adjusting for covariates, the MMSE score was lower among female participants, those with a lower educational level, those with mental labor occupations, and those with a higher speech recognition rate than among other groups. 
Wehave demonstrated that severe HLis associated with an increased risk of developing $\mathrm{Cl}$,manifesting as a lower MMSE score. In one study[23],HL affected episodic memory and attentional functions rather than executive functions. In fact, there is a large consensus that ARHL is an independent and modifiable risk factor for cognitive decline[24,25]. It is widely accepted that auditory deprivation triggers a vicious circle in older people, involving social isolation and $\mathrm{Cl}[26,27]$. Excessive cognitive load dedicated to auditory perceptual processing in everyday life causes structural changes in the brain and neurodegeneration, which are detrimental to other cognitive processes[28,29]. We combined subjective measures and objective audiometry in this studyanddiscovered that anincreased severityof $\mathrm{HL}$ and a poorer speech recognition rate were associated witha lower total MMSE score. Fetoni et al. [30]compared patients with and those without cognitive dysfunctionby means of the MMSE and discovered a higher hearing threshold in those with cognitive dysfunction $(p=0.049)$.

Our research also revealed a statistically significant correlation between educational level and cognitive function in four of the five MMSE subdomains (all except registration), even after adjustment for confounding factors. In the registration subdomain, participantsare scored on the repetition of three words (i.e., "tree,"'clock," and "car") on the first attemptafter the words were read out to them. When sufficient auditory stimuli were presented, all three words weretypically repeated correctly irrespective of theparticipant's educational level. In a Brazilian community sample, education also did not have an important effect on memory registration[31]. However, overall MMSE scores are highly dependent on educational level[32-34]. In a study of community-dwelling older adults aged 60 years or older,a higher educational level was associated with better cognitive function[35]. A higher educational level may provide sufficient cognitive reserve to counteract the effects of mild hearing impairment[36].

Our results support previous findings [10]that occupation type was related to cognitive function and may influence cognitive health through physiological and psychological pathways.Job stress may be a potential modifiable risk factor for adverse cognitive outcomes. In anepidemiological catchment area study in Baltimore [37],low-strain jobs were associated with statistically significantly lower decreases in cognitive scores than other job groups over an approximately eleven-year period.Normally, stress responses help individuals deal with urgent situations by activating the hypothalamus-pituitary-adrenal axis and increasing cortisol levels[38]. As a sense of low control is associated with high psychological stress, people with low job control bear higher risks of cognitive decline when facing high job demands[39]. Furthermore, a longer education, higher cognitive level of a person's occupation (such as white collar jobs, e.g., clerical work, medical practice, and other occupations requiring a university degree), and greater engagement in cognitive leisure activities were reportedly related to higher MMSE scores[40]. Theseresultssupportthe view that cognitive stimulation throughout the course of a person's life may contribute to cognitive reserve, thereby protecting that person against cognitive decline[41-43].

Across our cohorts, men generally performed better than womenforthe MMSEsubdomain of attention and calculation (but not the other subdomains)after adjustmentfor educational level. This result complements that of a report by the Lancet Commission[5]. However, only a few studies[44,45] have demonstrated the presence of sex differences in $\mathrm{MCl}$. Better attention and calculation performance in 
men than in women could arise from the effect of estrogen[46] or sex-specific cognitive reserve[5].An 8year longitudinal study revealed that cognitive deterioration in women with $\mathrm{MCl}$ was twice as fast as that in their male counterparts[47]. Even with the same degrees of hippocampal atrophy and the same rates of glucose metabolism in the temporal lobe, verbal memory performance reportedly differs between male and female patients with $\mathrm{MCl}$ [48]. The brain atrophy rate of female patients with $\mathrm{MCl}$ is reportedly higher than that of male patients, with an additional decrease of $1.0 \%-1.5 \%$ per year[49]. A possible explanation is that men may have higher resilience to MCl-related pathological damage to the brain [44] and better executive function than that exhibited bywomen, which is supported by the cognitive reserve theory.

The main strength of our study wasin the strictness ofthe inclusion and exclusion criteria, which may have reduced potential confounders.Another major strength was our ability to adjust for educational level to allow the comparison of sex differences among older adults, as educational level ishighly correlated with $\mathrm{MCl}$.However, there were also several limitations to our study. First, our results were based on crosssectional data rather than longitudinal trajectories of $\mathrm{HL}$ and cognitive function. Second, it was only a single-center study and, therefore,has limited reproducibility for older individuals. Third, we assessed cognitive function mainly with the MMSE.Future research should be focused on a more comprehensive approach forthe assessment of cognition, and longitudinal studies are neededto better explore the possible causal relationships between $\mathrm{HL}$ and cognitive function.

\section{Conclusions}

In the present study, we discovered statistically significant relationships between global cognitive function, as defined via the MMSE score, andsex, educational level, occupation type, and the speech recognition rate. Sex-specific strategies may be required to improve healthcare policies. These results indicate that the speech recognition ratemay be associated with cognitive impairment among older Chinese individuals, who should be screened routinely forthe early identification ofthe risk of cognitive decline. Our results need to be confirmed with prospective, longitudinal cohort studies.

\section{Abbreviations}

ARHL: age-related hearing loss

Cl: cognitive impairment

dB HL: decibels hearing level

HL: hearing loss

MCl: mild cognitive impairment

MMSE: Mini-Mental State Examination

PTA: pure-tone thresholds average 


\section{Declarations}

\section{Ethics Approval and Consent to Participate}

This study was approved by the Biomedical Research Ethics Committee of West China Hospital (No. 2020285). All participants voluntarily signed an informed consent form for participation in this study.

\section{Consent for Publication}

Not applicable.

\section{Availability of Data and Materials}

The datasets used and/or analysed during the current study are available from the corresponding author on reasonable request.

\section{Competing Interests}

The authors declare that they have no competing interests.

\section{Funding}

This work was supported by the 1.3 .5 project for disciplines of excellence-Clinical Research Incubation Project, West China Hospital, Sichuan University [No. 2020HXFH025]. The funder played no role in the design, collection, analysis, and interpretation of data of this study

\section{Authors' Contributions}

HG: Concept, design, literature search, and manuscript editing. XY: Data analysis, statistical analysis, and manuscript editing. CD, ML, WK, and HL: Data acquisition. YZ: Supervision. ZM: Manuscript review. All authors read and approved the final manuscript.

\section{Acknowledgements}

This research was supported by the Hearing Center/Hearing and Speech Science Laboratory, West China Hospital of Sichuan University, Chengdu, China. We wish to gratefully acknowledge Zhao Shi and Lingping Ding for data collection in this study.

\section{References}

1. Gauthier S, Reisberg B, Zaudig M, Petersen RC, Ritchie K, Broich K, et al. Mild cognitive impairment. Lancet. 2006;367:1262-70.

2. Eshkoor SA, Hamid TA, Mun CY, Ng CK. Mild cognitive impairment and its management in older people. Clin Interv Aging. 2015;10:687-93. 
3. International AD, Patterson C. World Alzheimer Report 2018: The state of the art of dementia research: New frontiers. 2018 [cited 2022 Jan 31]; Available from:

https://www.alzint.org/resource/world-alzheimer-report-2018/

4. Langa KM, Levine DA. The diagnosis and management of mild cognitive impairment: a clinical review. JAMA. 2014;312:2551-61.

5. Livingston G, Huntley J, Sommerlad A, Ames D, Ballard C, Banerjee S, et al. Dementia prevention, intervention, and care: 2020 report of the Lancet Commission. Lancet. 2020;396:413-46.

6. UhImann RF, Larson EB, Rees TS, Koepsell TD, Duckert LG. Relationship of hearing impairment to dementia and cognitive dysfunction in older adults. JAMA. 1989;261:1916-9.

7. Golub JS, Brickman AM, Ciarleglio AJ, Schupf N, Luchsinger JA. Association of Subclinical Hearing Loss With Cognitive Performance. JAMA Otolaryngol Head Neck Surg. 2020;146:57-67.

8. Liu C-J, Chang P-S, Griffith CF, Hanley SI, Lu Y. The Nexus of Sensory Loss, Cognitive Impairment, and Functional Decline in Older Adults: A Scoping Review. Gerontologist. 2021;gnab082.

9. US Preventive Services Task Force, Krist AH, Davidson KW, Mangione CM, Cabana M, Caughey AB, et al. Screening for Hearing Loss in Older Adults: US Preventive Services Task Force Recommendation Statement. JAMA. 2021;325:1196-201.

10. Stern Y, Gurland B, Tatemichi TK, Tang MX, Wilder D, Mayeux R. Influence of education and occupation on the incidence of Alzheimer's disease. JAMA. 1994;271:1004-10.

11. Boots EA, Schultz SA, Almeida RP, Oh JM, Koscik RL, Dowling MN, et al. Occupational Complexity and Cognitive Reserve in a Middle-Aged Cohort at Risk for Alzheimer's Disease. Arch Clin Neuropsychol. 2015;30:634-42.

12. Kremen WS, Beck A, Elman JA, Gustavson DE, Reynolds CA, Tu XM, et al. Influence of young adult cognitive ability and additional education on later-life cognition. Proc Natl Acad Sci U S A. 2019;116:2021-6.

13. Dekhtyar S, Wang H-X, Fratiglioni L, Herlitz A. Childhood school performance, education and occupational complexity: a life-course study of dementia in the Kungsholmen Project. Int $\mathrm{J}$ Epidemiol. 2016;45:1207-15.

14. Jones RN, Manly J, Glymour MM, Rentz DM, Jefferson AL, Stern Y. Conceptual and measurement challenges in research on cognitive reserve. J Int Neuropsychol Soc. 2011;17:593-601.

15. Wang J, Xiao LD, Wang K, Luo Y, Li X. Gender Differences in Cognitive Impairment among Rural Elderly in China. Int J Environ Res Public Health. 2020;17:3724.

16. Chou H-T, Wu P-Y, Huang J-C, Chen S-C, Ho W-Y. Late Menarche, Not Reproductive Period, Is Associated with Poor Cognitive Function in Postmenopausal Women in Taiwan. Int J Environ Res Public Health. 2021;18:2345.

17. Szoeke C, Downie SJ, Parker AF, Phillips S. Sex hormones, vascular factors and cognition. Front Neuroendocrinol. 2021;62:100927. 
18. Sundermann EE, Maki PM, Rubin LH, Lipton RB, Landau S, Biegon A, et al. Female advantage in verbal memory: Evidence of sex-specific cognitive reserve. Neurology. 2016;87:1916-24.

19. Chinese Medical Association $₫$ Chinese Medical Journals Publishing House $\llbracket$ Chinese Society of General Practice $\mathbb{E}$ Editorial Board of Chinese Journal of General Practitioners of Chinese Medical Association囚Expert Group of Guidelines for Primary Care of Cardiovascular Disease, Hu D. Guideline for primary care of hypertension (2019). Chin J Gen Pract. 301AD;18.

20. d'Emden MC, Shaw JE, Jones GR, Cheung NW. Guidance concerning the use of glycated haemoglobin (HbA1c) for the diagnosis of diabetes mellitus. Medical Journal of Australia. 2015;203:89-90.

21. Chinese Medical Association $₫$ Chinese Medical Journals Publishing House $₫$ Chinese Society of General Practice \Chronic Obstructive Pulmonology Group of Chinese Thoracic Society, Editorial Board of Chinese Journal of General Practitioners of Chinese Medical Association『Expert Group of Guidelines for Primary Care of Respiratory System Disease, Chen R, Sun Y. Guideline for primary care of chronic obstructive pulmonary disease (2018). Chin J Gen Pract. 2018;17:856-70.

22. World Health Organization. Programme for the Prevention of Deafness and Hearing Impairment. Future programme developments for prevention of deafness and hearing impairments: report of the first informal consultation, Geneva, 23-24 January 1997. Geneva: World Health Organization; 1997; Available from: https://apps.who.int/iris/handle/10665/63421

23. Guglielmi V, Marra C, Picciotti PM, Masone lacobucci G, Giovannini S, Quaranta D, et al. Does Hearing Loss in the Elderly Individuals Conform to Impairment of Specific Cognitive Domains? J Geriatr Psychiatry Neurol. 2020;33:231-40.

24. Anzivino R, Conti G, Di Nardo W, Fetoni AR, Picciotti PM, Marra C, et al. Prospective Evaluation of Cognitive Functions After Rehabilitation With Cochlear Implant or Hearing Aids: Preliminary Results of a Multicentric Study on Elderly Patients. Am J Audiol. 2019;28:762-74.

25. Fields TN, Mueller KD, Koscik RL, Johnson SC, Okonkwo OC, Litovsky RY. Self-Reported Hearing Loss and Longitudinal Cognitive Function in a Cohort Enriched with Risk for Alzheimer's Disease. J Alzheimers Dis. 2020;78:1109-17.

26. Fortunato S, Forli F, Guglielmi V, De Corso E, Paludetti G, Berrettini S, et al. A review of new insights on the association between hearing loss and cognitive decline in ageing. Acta Otorhinolaryngol Ital. 2016;36:155-66.

27. Strutt PA, Barnier AJ, Savage G, Picard G, Kochan NA, Sachdev P, et al. Hearing loss, cognition, and risk of neurocognitive disorder: evidence from a longitudinal cohort study of older adult Australians. Neuropsychol Dev Cogn B Aging Neuropsychol Cogn. 2020;1-18.

28. Uchida Y, Sugiura S, Nishita Y, Saji N, Sone M, Ueda H. Age-related hearing loss and cognitive decline - The potential mechanisms linking the two. Auris Nasus Larynx. 2019;46:1-9.

29. Kraus KS, Mitra S, Jimenez Z, Hinduja S, Ding D, Jiang H, et al. Noise trauma impairs neurogenesis in the rat hippocampus. Neuroscience. 2010;167:1216-26. 
30. Fetoni AR, Di Cesare T, Settimi S, Sergi B, Rossi G, Malesci R, et al. The evaluation of global cognitive and emotional status of older patients with chronic tinnitus. Brain Behav. 2021;11:e02074.

31. Laks J, Coutinho ESF, Junger W, Silveira H, Mouta R, Baptista EMR, et al. Education does not equally influence all the Mini Mental State Examination subscales and items: inferences from a Brazilian community sample. Braz J Psychiatry. 2010;32:223-30.

32. Spering CC, Hobson V, Lucas JA, Menon CV, Hall JR, O'Bryant SE. Diagnostic accuracy of the MMSE in detecting probable and possible Alzheimer's disease in ethnically diverse highly educated individuals: an analysis of the NACC database. J Gerontol A Biol Sci Med Sci. 2012;67:890-6.

33. O’Bryant SE, Humphreys JD, Smith GE, Ivnik RJ, Graff-Radford NR, Petersen RC, et al. Detecting dementia with the mini-mental state examination in highly educated individuals. Arch Neurol. 2008;65:963-7.

34. Nakahata N, Nakamura T, Kawarabayashi T, Seino Y, Ichii S, Ikeda Y, et al. Age-Related Cognitive Decline and Prevalence of Mild Cognitive Impairment in the Iwaki Health Promotion Project. J Alzheimers Dis. 2021;84:1233-45.

35. Harithasan D, Mukari SZ-MS, Ishak WS, Shahar S, Yeong WL. The impact of sensory impairment on cognitive performance, quality of life, depression, and loneliness in older adults. Int J Geriatr Psychiatry. 2020;35:358-64.

36. Alattar AA, Bergstrom J, Laughlin GA, Kritz-Silverstein D, Richard EL, Reas ET, et al. Hearing Impairment and Cognitive Decline in Older, Community-Dwelling Adults. J Gerontol A Biol Sci Med Sci. 2020;75:567-73.

37. Dong L, Eaton WW, Spira AP, Agnew J, Surkan PJ, Mojtabai R. Job strain and cognitive change: the Baltimore Epidemiologic Catchment Area follow-up study. Occup Environ Med. 2018;75:856-62.

38. Lupien SJ, McEwen BS, Gunnar MR, Heim C. Effects of stress throughout the lifespan on the brain, behaviour and cognition. Nat Rev Neurosci. 2009;10:434-45.

39. Agrigoroaei S, Lachman ME. Cognitive functioning in midlife and old age: combined effects of psychosocial and behavioral factors. J Gerontol B Psychol Sci Soc Sci. 2011;66 Suppl 1:i130-140.

40. Ihle A, Gouveia ÉR, Gouveia BR, Freitas DL, Jurema J, Odim AP, et al. The relation of education, occupation, and cognitive activity to cognitive status in old age: the role of physical frailty. International Psychogeriatrics. Cambridge University Press; 2017;29:1469-74.

41. Darwish H, Farran N, Assaad S, Chaaya M. Cognitive Reserve Factors in a Developing Country: Education and Occupational Attainment Lower the Risk of Dementia in a Sample of Lebanese Older Adults. Front Aging Neurosci. 2018;10:277.

42. Vance DE, Eagerton G, Harnish B, McKie-Bell P, Fazeli PL. Cognitive Prescriptions: A Nursing Approach to Increasing Cognitive Reserve. J Gerontol Nurs. 2011;37:22-31.

43. Zhu W, Li X, Li X, Wang H, Li M, Gao Z, et al. The protective impact of education on brain structure and function in Alzheimer's disease. BMC Neurol. 2021;21:423.

44. Li X, Zhou S, Zhu W, Li X, Gao Z, Li M, et al. Sex Difference in Network Topology and Education Correlated With Sex Difference in Cognition During the Disease Process of Alzheimer. Front Aging 
Neurosci. 2021;13:639529.

45. Narbutas J, Chylinski D, Van Egroo M, Bahri MA, Koshmanova E, Besson G, et al. Positive Effect of Cognitive Reserve on Episodic Memory, Executive and Attentional Functions Taking Into Account Amyloid-Beta, Tau, and Apolipoprotein E Status. Front Aging Neurosci. 2021;13:666181.

46. Ancelin ML, Ritchie K. Lifelong endocrine fluctuations and related cognitive disorders. Curr Pharm Des. 2005;11:4229-52.

47. Lin KA, Choudhury KR, Rathakrishnan BG, Marks DM, Petrella JR, Doraiswamy PM, et al. Marked gender differences in progression of mild cognitive impairment over 8 years. Alzheimers Dement $(\mathrm{N}$ Y). 2015;1:103-10.

48. Sundermann EE, Biegon A, Rubin LH, Lipton RB, Mowrey W, Landau S, et al. Better verbal memory in women than men in $\mathrm{MCl}$ despite similar levels of hippocampal atrophy. Neurology. 2016;86:136876.

49. Ardekani BA, Convit A, Bachman AH. Analysis of the MIRIAD Data Shows Sex Differences in Hippocampal Atrophy Progression. J Alzheimers Dis. 2016;50:847-57.

Figures

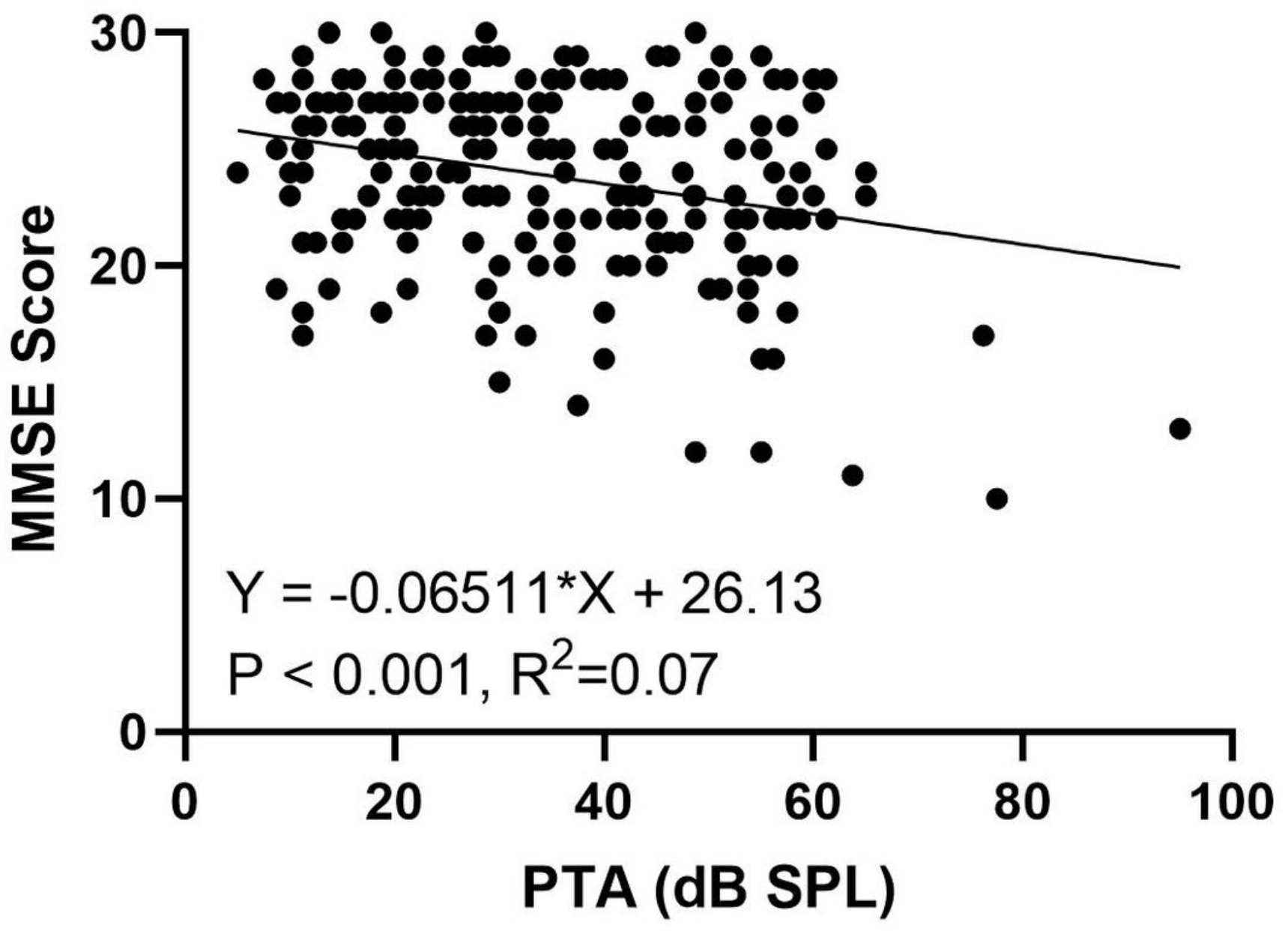


Figure 1

Caption not included with this version.

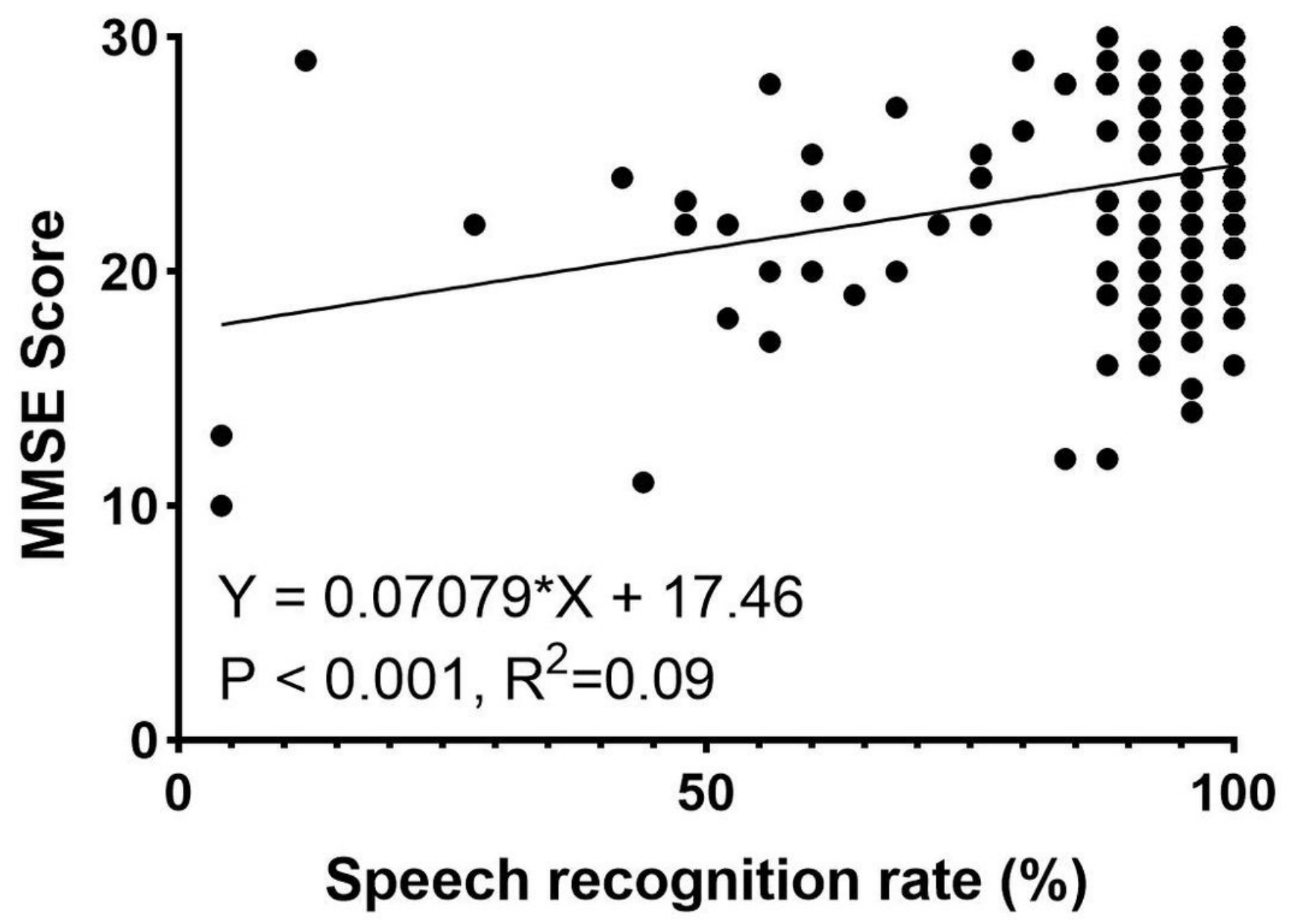

Figure 2

Caption not included with this version. 


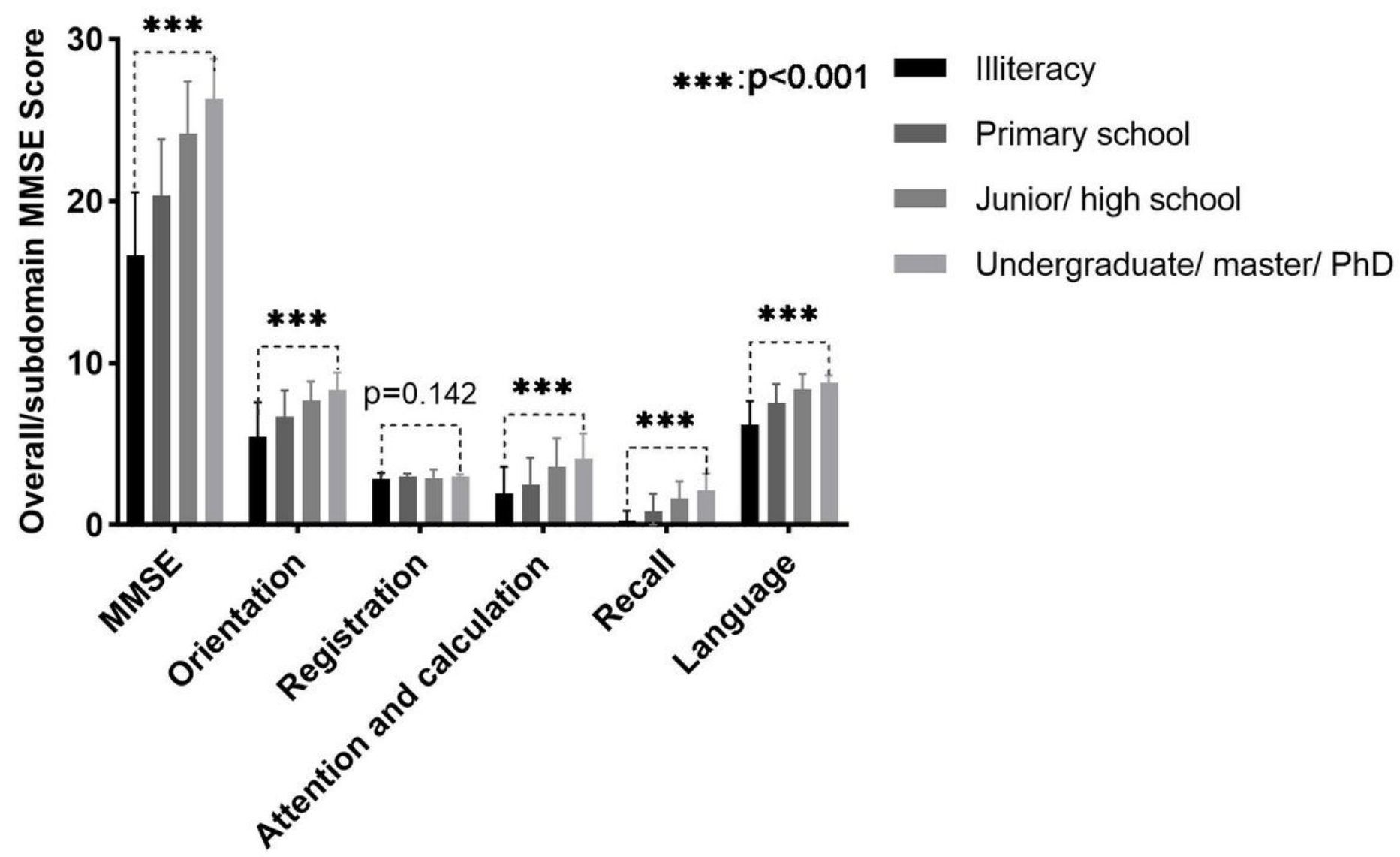

Figure 3

Caption not included with this version. 


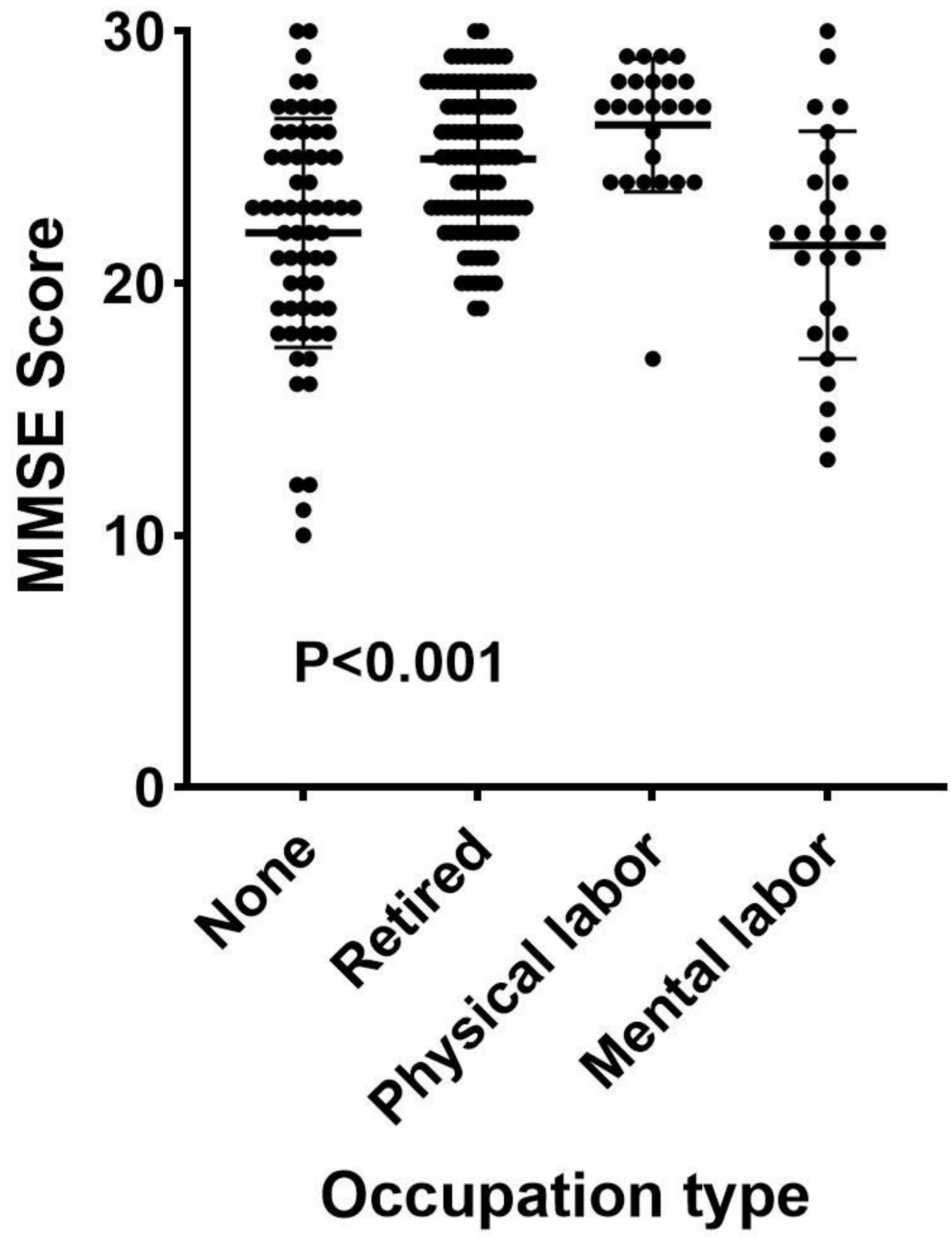

Figure 4

Caption not included with this version. 


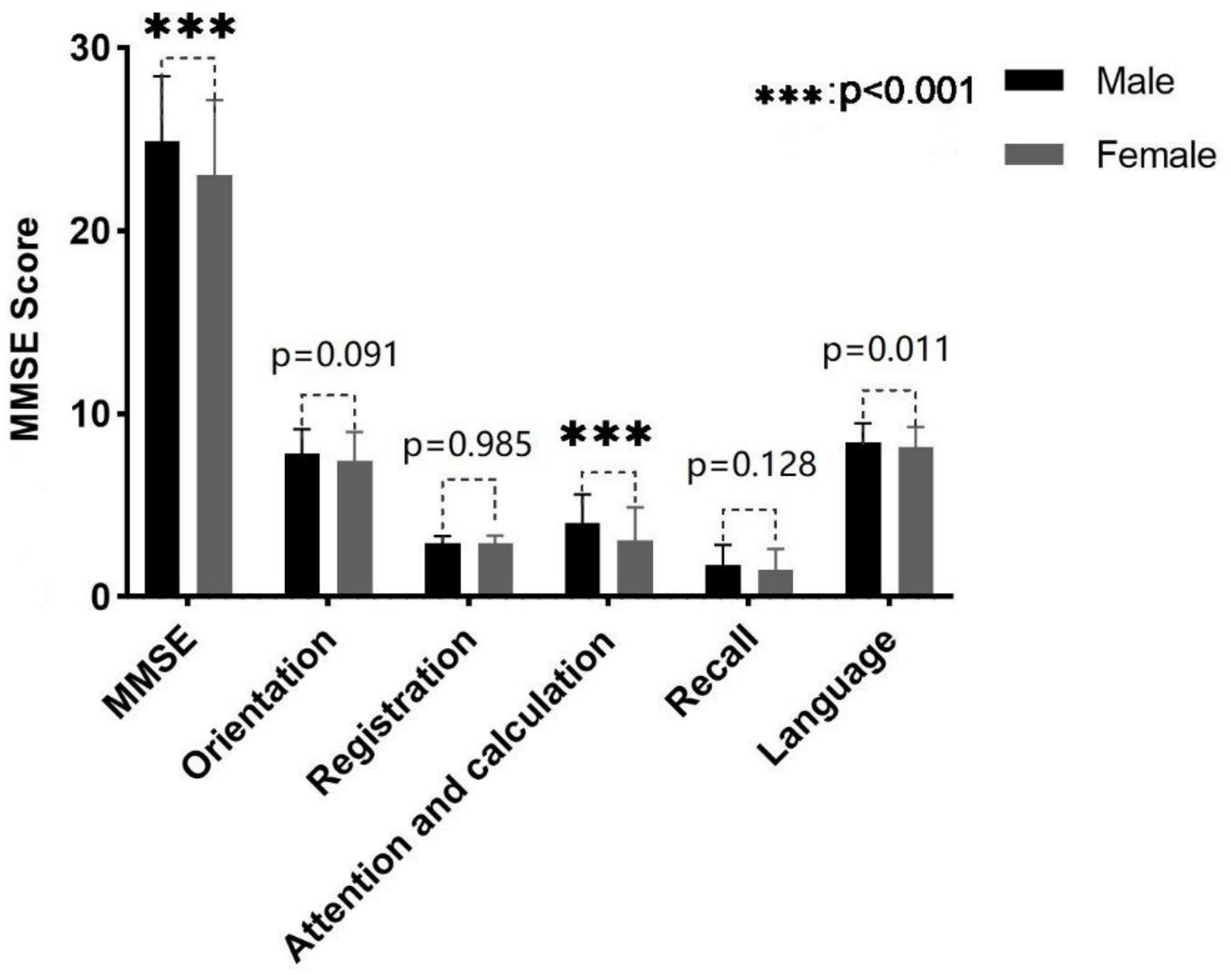

Figure 5

Caption not included with this version. 